\title{
Closed Loop Control of Bi-Directional DC-DC Converter
}

\author{
Pratapsinh G. Parmar ${ }^{1}$, Urvashi D. Patel ${ }^{2}$, Manish S. Patel ${ }^{3}$ \\ PG Scholar, Department of Electrical Engineering, Ganpat University, Kherva, India ${ }^{1}$ \\ Assistant Professor, Department of Electrical Engineering, Ganpat University, Kherva, India ${ }^{2,3}$
}

\begin{abstract}
This paper presents a closed loop control of isolated boost full bridge DC-DC converter for used in Medium and High power application. Zero voltage switching is applied in all switches. The DC input voltage is stepped up by using a boost converter. It is inverted using a full bridge inverter. The transformer is used to produce a higher voltage in secondary voltage side. The a.c. Voltage is converted into D.C. Voltage with the help of rectifier. The open loop model, there is no possibility of maintaining a constant voltage with a variation of input voltage. In closed loop system is maintaining a constant voltage is applied with various value of input voltage. The Matlab version is used for simulating the open loop and closed loop full bridge DC - DC converter are verified.
\end{abstract}

Keywords: Bidirectional power flow, zero voltage switching, full bridge, isolated boost converter.

\section{INTRODUCTION}

Isolated boost full bridge DC-DC converter is used for medium and high power application. It is an alternative source of electrical energy. Fig. 1 shows the block diagram of isolated boost full bridge DC-DC converter. The input voltage is applied to the boost converter to boost the voltage. A full bridge inverter is used to convert the DC voltage into $\mathrm{AC}$ voltage.

The transformer is used to step up the AC voltage and also isolate the low voltage and high voltage. The rectifier is converted into AC voltage into DC voltage. It is applied to the resistive load. In forward direction the low voltage side to high voltage side the circuit works in boost mode. On reverse direction high voltage side to the low voltage side the circuit works in block mode.

The harmonic current pollution of the AC power systems is being restrained by international standard [1]. A dual active full bridge DC-DC converter for high power, bidirectional application [2]. A dual active half bridge soft switching bidirectional, avoiding voltage spike issue in a current fed inverter [3]. The converter operates in continuous conduction mode with soft commutation of the control switches and constant frequency pulse width modulation [4-7].

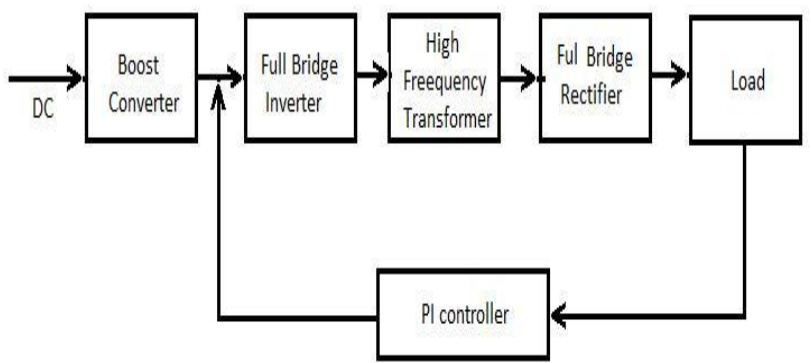

Fig. 1: Block Diagram of Closed Loop Boost Full Bridge DC-DC converter

The duty cycle $\delta$ of the two pulse width modulated signals produced by Matlab are synchronized with $180^{\circ}$ phase shift [8]. The isolated boost full bridge topology can converter low input voltage to high output voltage [9]. The simulation of full bridge DC-DC converter using both the control scheme was implemented in Matlab 7.3 version simulation tool and found that phase shifted control scheme is better than the conventional scheme [10-11]. This paper deals with PI controller is proposed the open loop does not maintain the constant voltage with the variation of input. The closed loop system maintains constant voltage with the variation of input voltage.

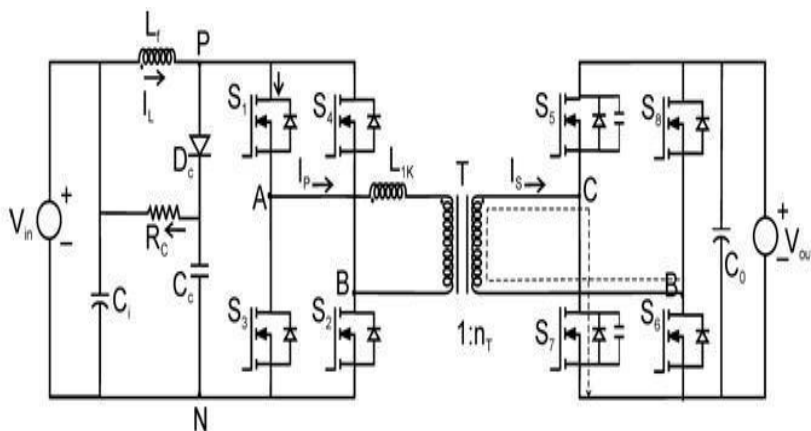

Fig. 2: Isolated Boost Full bridge DC-DC Converter

\section{OPERATING PRINCIPLE}

The operating principle is divided into two modes i) Energy is storing mode ii) Energy is transforming mode. At initial condition, the input voltage is applied to the inductor energy is stored in the inductor. $\mathrm{S}_{1}-\mathrm{S}_{4}$ switches are ON condition for the fraction of seconds. In buck mode operation four $\mathrm{ON}$ and two OFF switches. The converter operates in two modes in-between the commutating mode is operated.

$\mathrm{S}_{1}-\mathrm{S}_{4}$ are turned $\mathrm{ON}$. Inductor stores energy corresponding current increases linearly. $\mathrm{S}_{7}, \mathrm{D}_{6}$ are $\mathrm{ON}$ the current through the primary winding of the transformer is short circuited. To create a freewheeling flow part are $S_{7}, D_{6}$. $\mathrm{S}_{6}$ can be turned $\mathrm{ON}$ after zero voltage condition.

$\mathrm{S}_{3}, \mathrm{~S}_{4}$ are turned OFF. The voltage is charged quickly by the balance current up to the active clamping. $\mathrm{S}_{7}, \mathrm{D}_{6}$ are remains $\mathrm{ON}$. 
At the condition $\mathrm{I}_{\mathrm{L}}-\mathrm{I}_{\mathrm{P}}$, after commutating ends and the \& fig. 16. The output power with efficiency as shown in converter is waiting for energy transferring mode. $S_{7}, D_{6}$ fig. 17. are remains $\mathrm{ON}$. The secondary side of the transformer remains ON drops from zero. Energy is stored in inductor again. $\mathrm{S}_{7}$ is turned OFF $\mathrm{D}_{5}$ is turned $\mathrm{ON}$. $\mathrm{D}_{5}$ and $\mathrm{S}_{6}$ are transferring energy from primary side to the secondary side of the converter. $\mathrm{S}_{5}$ is $\mathrm{ON}$. Under zero voltage switching and prepares the next commutating modes. $\mathrm{I}_{\mathrm{s}}=\mathrm{I}_{\mathrm{L}}$, Energy transferring mode ends. $\mathrm{S}_{5}, \mathrm{D}_{8}$ to create current freewheeling path to change its direction. $D_{6^{-}} S_{5}$ remains $\mathrm{ON}$ until it resets to zero. After the resonate period. $\mathrm{D}_{8}$ forming a freewheeling path and a leakage current path through $\mathrm{S}_{5}-\mathrm{D}_{8}$. Again the cycle is repeated $\mathrm{S}_{1}-\mathrm{S}_{4}$ are turned $\mathrm{ON}$

\section{III.DESIGN GUIDE LINES}

\section{Losses}

1. The conduction losses in the rectifier are the same for conventional PWM and ZVS PWM. Prect $=4$ (Iout $/ 2$ Vf). $V_{f}$ is the forward drop for the rectifier diodes, assuming that a full bridge rectifier is used.

2 . The conduction losses on the primary bridge diodes are $\mathrm{PD}=$ Vdiode Iav. $\mathrm{V}_{\text {diode }}$ is the forward voltage drop on the diodes and $\mathrm{I}_{\mathrm{av}}$ is the average current.

3. The conduction losses due to channel resistance of the switches can be calculated as $\mathrm{P}_{\mathrm{Q}}=\mathrm{R}_{\text {on }} \mathrm{I}_{\mathrm{rms}}$ To find parameters.

$$
\begin{aligned}
& \mathrm{L}=\mathrm{V}_{\mathrm{o}} \delta / \mathrm{f} \Delta \mathrm{I} \\
& \mathrm{I}_{\mathrm{o}}=\mathrm{V}_{\mathrm{o}} / \mathrm{R} \\
& \mathrm{E}_{1}=4.44 \mathrm{~N}_{1} \\
& \Phi f \mathrm{E}_{2}=4.44
\end{aligned}
$$

$\mathrm{N}_{2}$ Фf Losses:

$$
\begin{aligned}
& \text { Mosfet }=8 \mathrm{x} 2 \mathrm{w}=16 \mathrm{w} \\
& \text { Transformer }=12 \mathrm{w} \\
& \text { Inductor }=5 \mathrm{w} \\
& \text { Resistor }=10 \mathrm{w}
\end{aligned}
$$

\section{IV.SIMULATION RESULTS}

ZVS-PWM D.C. to D.C. converter is simulated using mat lab and the simulation results are presented. The primary side four MOSFET switches and four diodes is used in the secondary side of the transformer. The circuit model of isolated boost ZVS-PWM D.C to D.C. converter is shown in Fig 3. DC input voltage is $15 \mathrm{~V}$ as shown in fig. 3. The square Pulse width is applied with constant frequency and voltage across M3 are shown in fig 4. and M4 are shown in Fig 5. The inverter output voltage is shown in Fig 6. The transformer is stepped up the voltage and then converted A.C into D.C with capacitor is connected across the load output voltage across load is shown in Fig 7. the four switches at the voltage fed inverter side are also verified under soft switching condition The harmonics across the inverter voltage is shown in Fig 8. The D.C to D.C converter operating in buck mode is shown in Fig 10. The driving pulses for MOSFETS M1 and M2 are shown in fig 11 . The dc input voltage is 50 voltages as shown in fig 12. The transformer primary voltage is shown in fig 13. The transformer secondary voltage is shown in fig 14 . The Output voltage is shown in Fig 15. Variation of output with input for boost and buck modes are shown in Fig.3g
The open loop converter using an input voltage of $12 \mathrm{v}$ is simulated under the condition, below

$$
\begin{aligned}
\mathrm{V}_{\mathrm{IN}=15 \mathrm{~V}}, \mathrm{C}_{\mathrm{o}}=300 \mu \mathrm{f}, \mathrm{V}_{\mathrm{o}}=58 \mathrm{~V}, \delta=0.5, \mathrm{C}_{\mathrm{c}=1500 \mu \mathrm{f}, \mathrm{R}_{\mathrm{c}}} \\
=2000 \Omega, \mathrm{L}=350 \mu \mathrm{H}, \mathrm{f}=55 \mathrm{khz}
\end{aligned}
$$

\section{BOOST MODE}

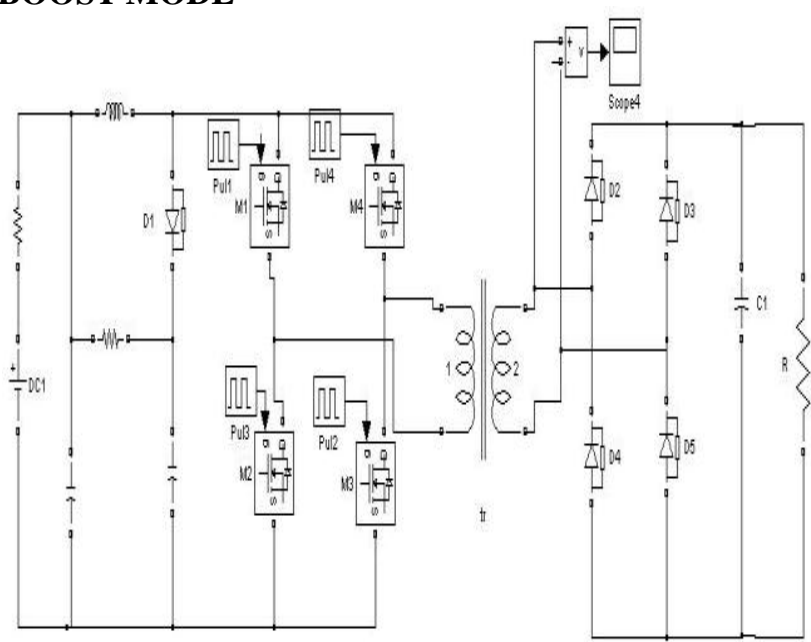

Fig.3: Circuit Diagram

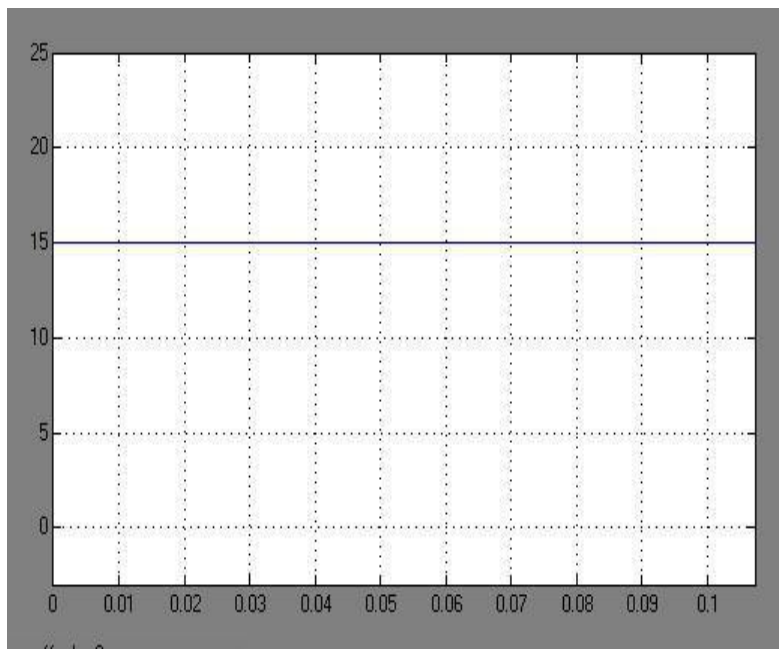

Fig. 4: Dc input Voltage

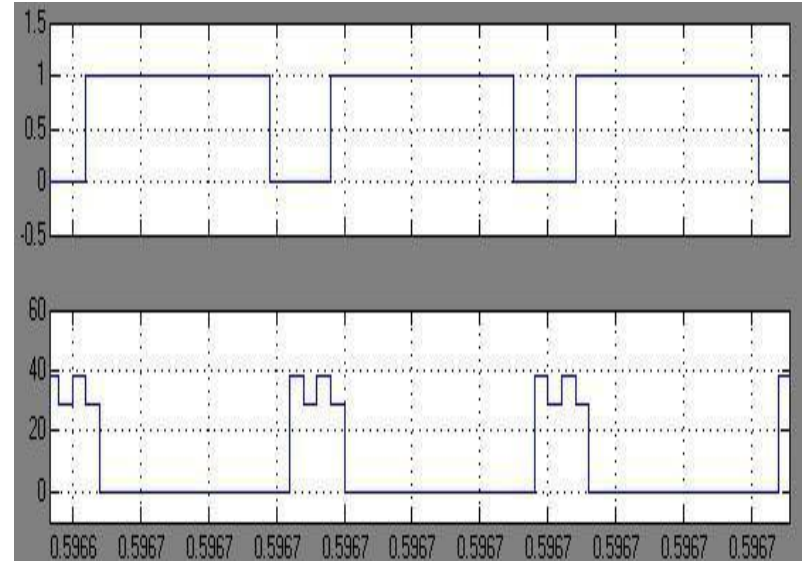

Fig. 5: Pulse and Voltage across M3 
INTERNATIONAL JOURNAL OF INNOVATIVE RESEARCH IN ELECTRICAL, ELECTRONICS, INSTRUMENTATION AND CONTROL ENGINEERING Vol. 4, Issue 2, February 2016

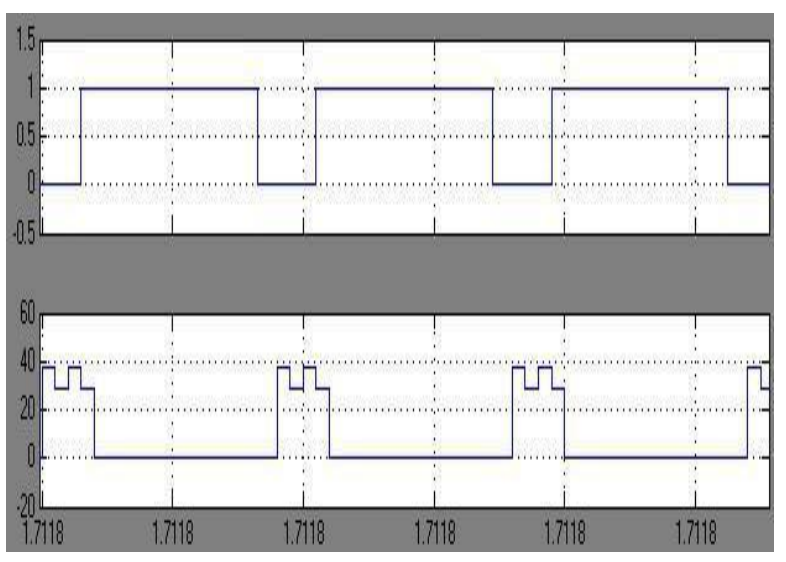

Fig. 6: Pulse and Voltage across M4

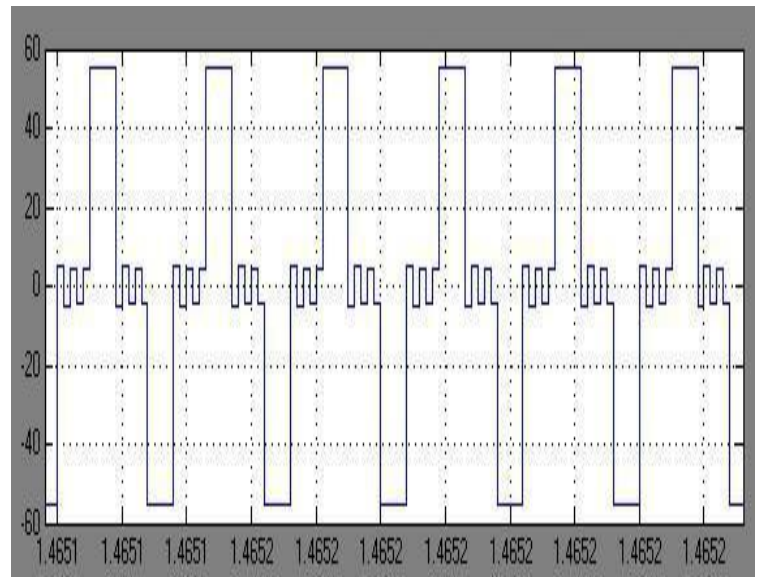

Fig.7: Inverter output voltage

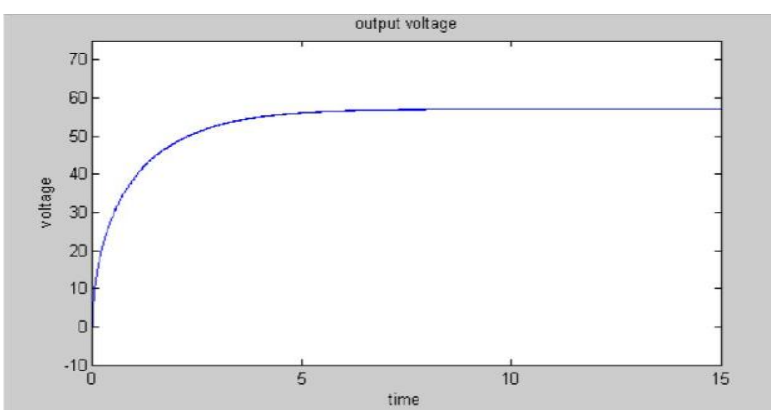

Fig. 8: DC output voltage

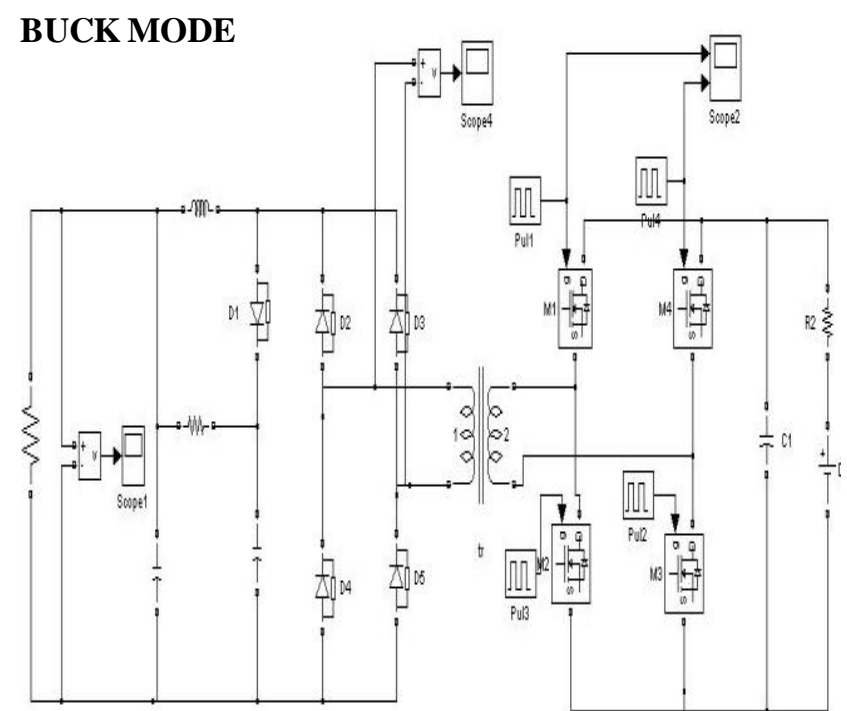

Fig.9: Circuit Diagram

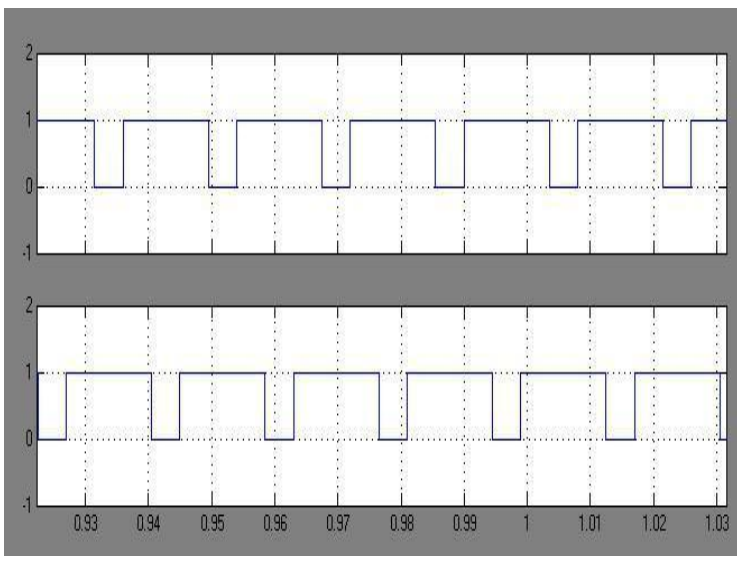

Fig 10: Driving pulses for M1 and M2

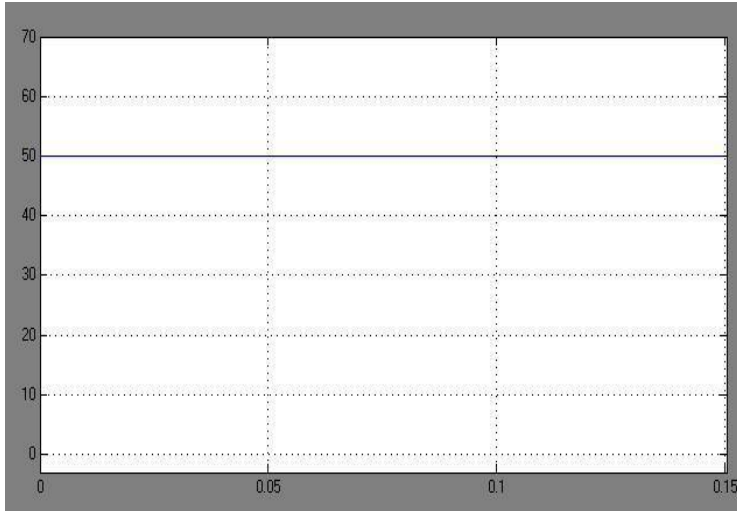

FIG. 11: DC INPUT VOLTAGE

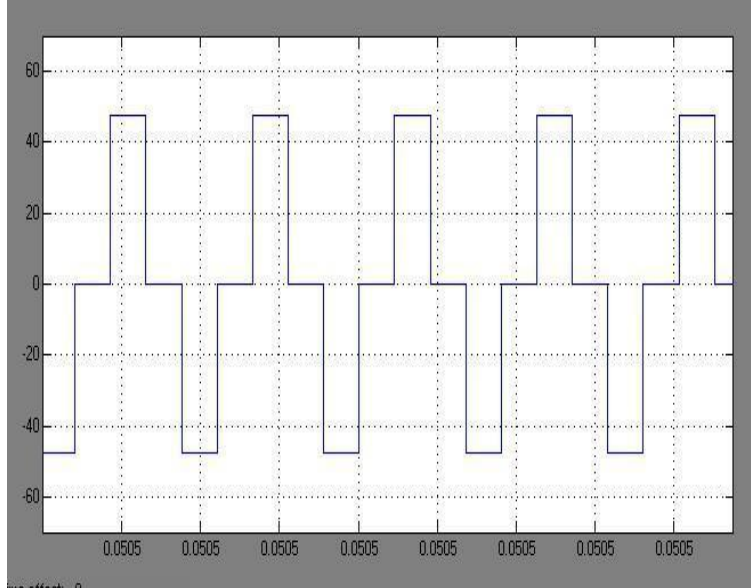

Fig. 12: transformer primary voltage

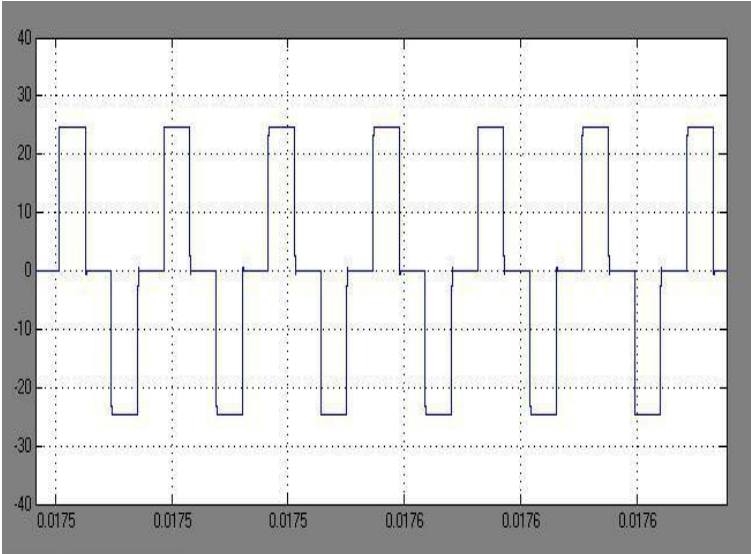

Fig. 13: transformer secondary voltage 
INTERNATIONAL JOURNAL OF INNOVATIVE RESEARCH IN ELECTRICAL, ELECTRONICS, INSTRUMENTATION AND CONTROL ENGINEERING

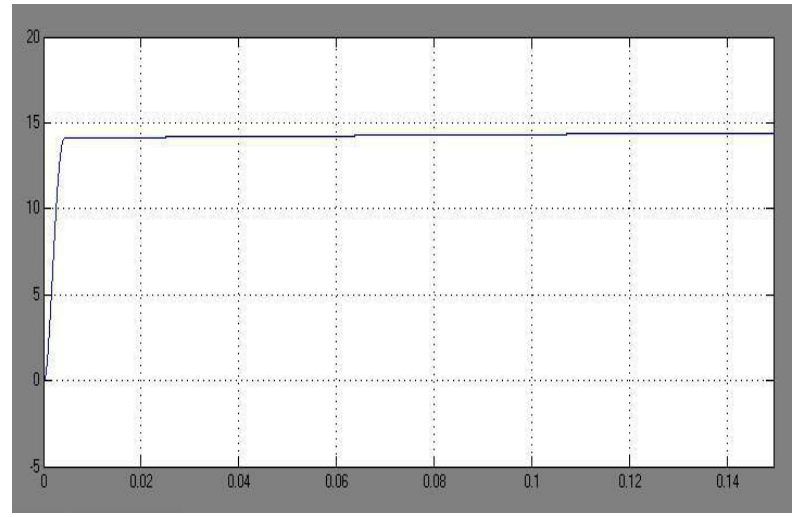

Fig.14: DC Output voltage

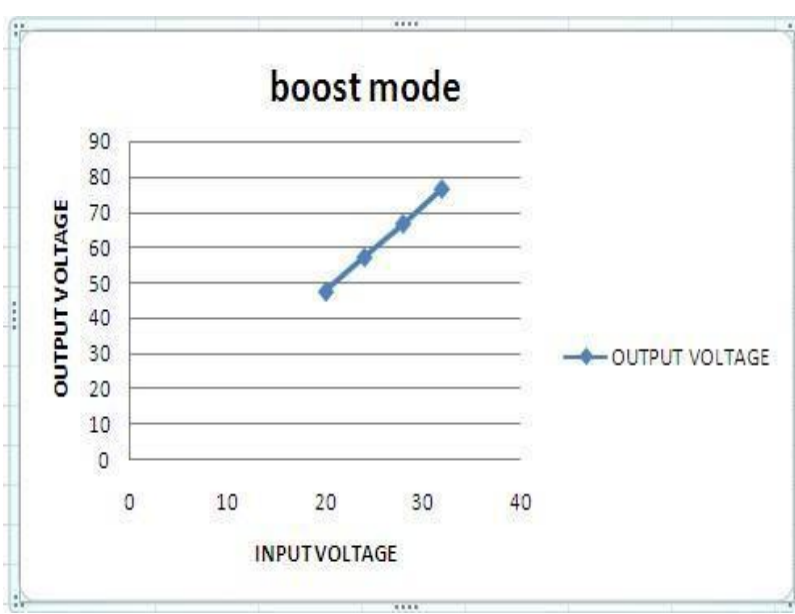

Fig.15: OUTPUT Voltage Vs InPUT Voltage

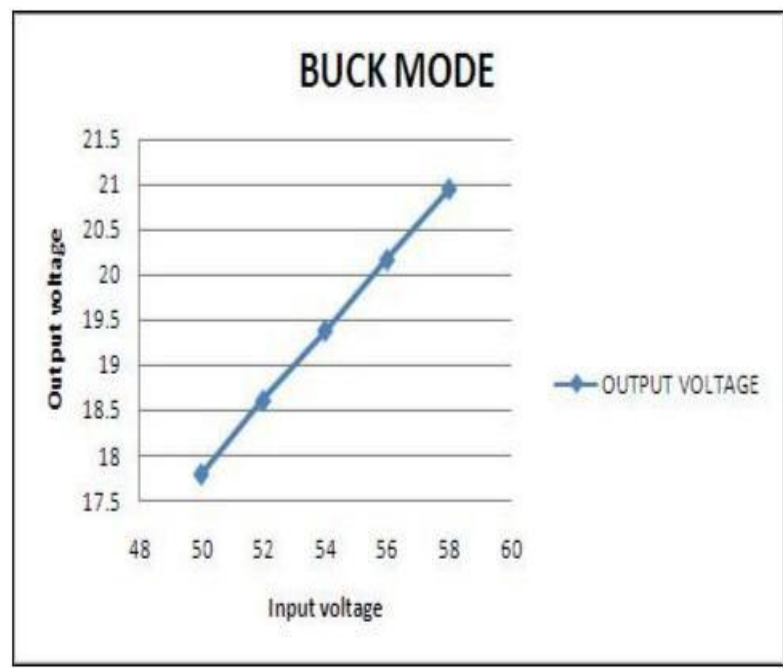

Fig. 16: OUTPUT Voltage Vs InPUT VolTAGE

\begin{tabular}{|c|c|}
\hline Output power $(\mathbf{W})$ & efficiency \\
\hline 112.8 & 96.4 \\
\hline 135 & 92.5 \\
\hline 139.3 & 91.1 \\
\hline 154.56 & 90.4 \\
\hline
\end{tabular}

Table - 1

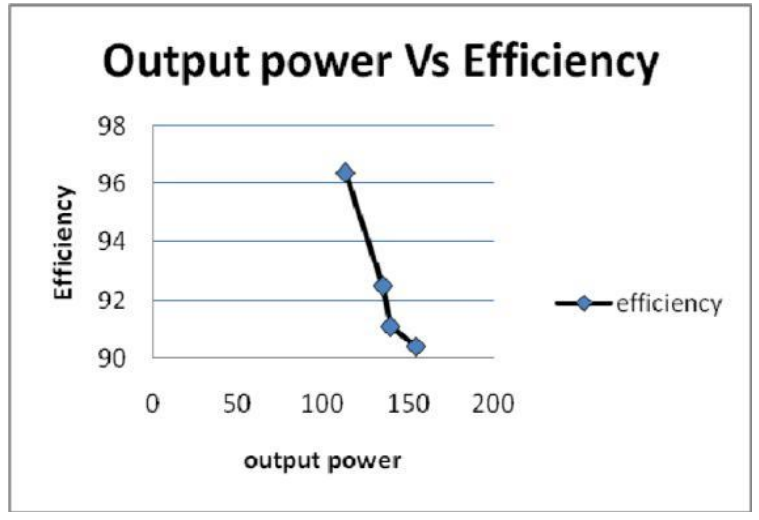

Fig.17: output power Vs Efficiency

The circuit model of the closed loop system is shown in Fig 19. Output voltage is sensed and it is compared with the reference voltage. The error is applied to a PI controller. The output of PI controller is used to generate proper pulses to drive the MOSFET in the output rectifier. A controlled converter is recommended at the to get a constant voltage across the load. The response of closed loop system is shown in Fig 20. From this figure, it can be seen that the output voltage increases, oscillates and is reduced to the set value of $250 \mathrm{~V}$.

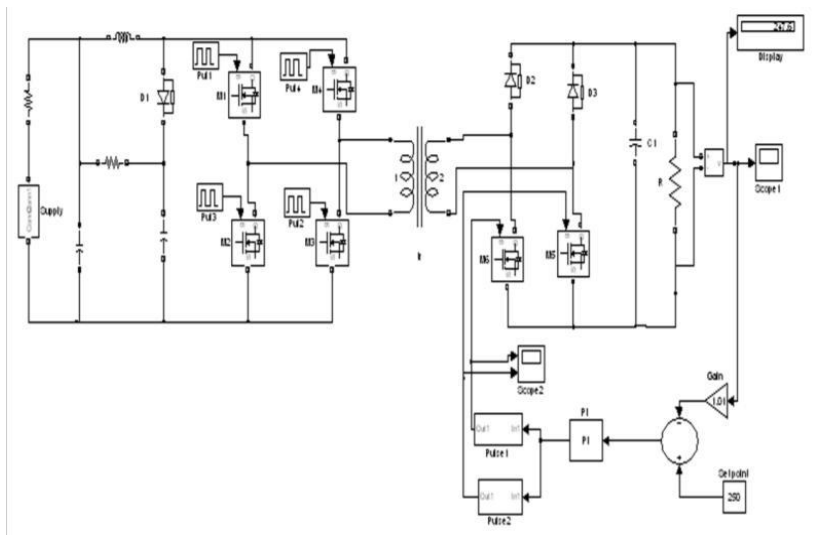

Fig. 18: Closed loop circuit diagram

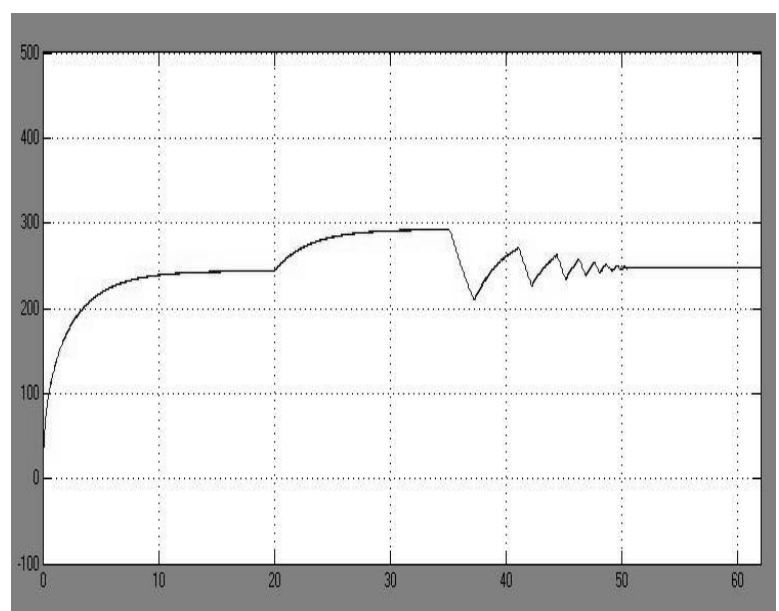

FIG. 19: OUTPUT VOLTAGE WITH DISTURBANCE

\section{CONCLUSION}

Bidirectional power flow control and conversion capability and with electrical. Isolation between the two 
sides through a transformer are evaluated for medium and high power application with consideration of device availability and a preliminary design study, a circuit configuration with the current fed converter on the LV low side and the voltage fed converter on the $\mathrm{HV}$ side is arranged the peak charging mode efficiency reaches $96 \%$ with full bridge version, but only $90 \%$ of full bridge converter is more efficient because it allows lower voltage devices to be used, and the active clamp circuit provides lossless operation. The open loop and closed simulation can be presented. The advantages of Boost converter are also obtained by adding Boost converter at the input side. This circuit is capable of performing D.C.to D.C. Conversion with high efficiency. The circuit using PI controller to maintain a constant with various value of input.

\section{REFERENCES}

11] T.S. Key and J.S. Lai, "IEEE and international harmonic standards impact on power Electronic design", in Proc. Virgina Power Electron Sem (VPEC), 1988 PP, 39-45.

[2] Lizhizhu "A Novel soft commutation Isolated Boost Full bridge ZVS-PWM DC-DC converter for Bidirectional High Power applications in IEEE Transactions on Power Electronics Vol.21, No.2, March 2006

[3] Z Peng, Hui Li and Jack S.Kawler "New ZVS bidirectional DC-DC converter for fuel cell and battery application in IEEE transaction on power Electronics Vol.19 No.1, January 2004.

[4] B. Carsten, "Design techniques for transformers active reset circuits at high frequencies and power levels" in Proc. High frequency power conf (HFPC) conf., 1990 PP, 235-246.

5] C.M.C. Duarte and I.Barbi, "A family of ZVS-PWM active clamping D.C. to D.C. converters, Synthesis, analysis, design and experimentation”, „IEEE Trans, circuits system, vol 44, PP 698 704 Aug 1997.

[6] R.T. Bascope and I. Barbi, "a double ZVS-PWM active clamping forward converter in proc. IEEE Appl. Power Electronics Conf expo (APEC) 1999, PP 596-601.

[7] Zhu, Kurong Wang, Fred C. Lee, Jih-Shang-Lai, “ New Start UP schemes for Isolated boost full bridge boost converters, proc. IEEE Power Electronics trans 2003, PP 946-951.

[8] R. Watson, F.C. Lee, "A soft switched full bridge boost converter employing and active-clamp circuit", in proc IEEE PSEC, 1986, PP 1948-1954.

[9] M. Zimmermann, G.D. Silva, A. Peres E. Deschamps, "PWM strategies for high voltage Isolated dc-dc converter for rectifier system", IEEE Telecommunication conference, PP 415-420, Sep 2005 .

[10] Elton pepa, "Adaptive control of a step up full bridge dc-dc converter for variable low input voltage applications. M.S. Thesis Department of Electrical Engg. Virginia Polytechnic institute and state university, Virginia, USA, 2004.

[11] Lizhizhu, "A Novel soft commutating Isolated Boost full bridge ZVS-PWM dc-dc converter for Bidirectional High power Application", IEEE Transactions on power Electronics Vol 21 No.2, March 2006. 